\title{
Practice research partnerships in social work: Making a difference
}

\author{
Christa Fouché \\ Policy Press, Bristol, 2015 \\ ISBN 978-1-4473-1401-1, pp.208, paperback, NZD73.00
}

$\mathrm{I}$ was pleased to have the opportunity to review Practice Research Partnerships in Social Work as I have had an abiding interest in and engagement with practice research and wanted to see how some of the 'messiness' these types of creative and collaborative endeavours would be written about. I was not disappointed. Christa Fouché has put together a text that is aimed at social workers to use in their organisations to conduct practice research. The sub-title for the text 'Making a difference' is a theme throughout all of the nine chapters. Fouché ably articulates how practice research can make a positive difference on many levels. This includes: with the clients social workers serve; with the organisations social workers practice in; at a policy and legislative level; in communities and neighbourhoods, and for the profession as a whole.

The text is divided into three equal parts with the three chapters in Part One focusing on the relationship between practice and research. Designing practice research is covered in three further chapters in Part Two. Part Three considers nurturing networks for the purpose of conducting practice research. I was somewhat surprised to read a statement right at the beginning of the book that Part One "would not be of great interest to emerging practice researchers" (xii). While I am an experienced researcher myself, I did try out some of the excellent reflective questions raised in the first three chapters with a group of people who are emerging practice researchers and we all found them to be searching and professionally challenging to consider. An example, from Chapter One is 'How do you know what you do is at the very least doing no harm, but at best making a difference?' (2015, p4). How important is that question for all of us to consider in our work, not just every now and then, but often? While this book is designed for people at the beginning of developing knowledge and skill in practice research Fouché treats her readers with respect and poses complex and gritty questions like the one above throughout. I thought the sets of reflective questions alone (33 in total) made buying the book worthwhile. These questions could be considered as part of everyday practitioner supervision.

In the first set of three chapters Fouché presents her arguments about why practice research is so very important for social workers to undertake. She draws on plenty of sources noting social work practitioners have traditionally not been amendable to engaging with research to guide practice, or producing their own research. In these chapters Fouché draws attention to the relational aspect of research and writes convincingly about how as practitioners social workers know how to 'do' relationship work, with this knowledge and skill being critical for success in practice research.

In the three chapters that make up Part Two of the book, Fouché writes about the research process as including five overlapping phases: framing the research questions; designing the method for conducting the research; collecting the data; analysing the data and reporting the data'. These chapters provide a clear overview of essentials that practitioner researchers need to consider 
during each phase, and for the life of the project. Part Two includes a series of Tables that summarise key points such as methods for data collection and considerations for project management. Fouché is overt about the research process being iterative but at the same time having its own internal logic by following through the phases. In using this writing style she answered my initial question of how would a writer deal with the messiness of practice research. It is clear from the examples of projects that Fouché cites that she has had in-depth involvement with many practice research initiatives. I had a slight disappointment that certain projects she wrote about as examples in the text did not contain references to where I could find out more about them. Even so the knowledge gained from involvement in so many grassroots projects has been so well articulated in this book.

Part Three of the text is about dissemination of the research results, making and keeping research connections, and mentoring during research. Fouché quite rightly notes that dissemination of findings, even when they are problematic is both an ethical activity as well as a knowledge producing endeavour.
She eloquently makes the point that when there are unexpected or disappointing findings from research these are just as valuable to the professional community as affirming results. This is an important take home message for readers and researchers.

The narrative in this book is invitational, encouraging readers to consider the application of practice research in their own workplace setting. The writing style is engaging, asking the reader to consider how different research initiatives might work in the readers own organisation. I used highlighters and sticky notes throughout to draw attention to what I considered to be important ideas, and when I finished reading I realised that the whole text was one very big important idea. This book could very easily be used by a group of colleagues in an organisation or across organisations to work their way through a practice research project. I encourage social workers to have a go at developing their own project and to use this book as a guide. There is plenty of professional learning to be had both in the reading and the doing of practice research, under the able guidance of Christa Fouché. 